\title{
Fuerzas profundas y nuevos conflictos en la post Primavera árabe
}

\author{
Rubén Paredes Rodríguez*
}

\section{Resumen}

La Primavera árabe ha sido un proceso transnacional que afectó a los países árabes que se encuentran diseminados por la región del Middle East and Nord Africa -MENA por su acrónimo en inglés-. A pesar de las esperanzas que se cifraron con el despertar de las sociedades, las incertidumbres que rodearon dicho proceso fueron cristalizándose en la presencia de fuerzas profundas que han estado operando en la región.

En tal sentido, el presente artículo busca analizar en el contexto del MENA la configuración de dos fuerzas profundas en la post Primavera árabe, a través de las cuales se puede reconstruir el contexto en el que operan y se desenvuelven, como así también identificar a los actores involucrados con sus acciones e intereses. Ellas son el retorno del autoritarismo y la identificación de todo el Islam político como enemigo.

Si bien no se pierde de vista que éstas se encuentran interrelacionadas, a los fines metodológicos se las aborda por separado atendiendo a cómo fueron tomando forma en el transcurso de la década y a cómo se manifestaron en diferentes momentos en el contexto regional del MENA. Esto permitirá entender la naturaleza abierta de los conflictos que se suscitaron en Libia, Yemen y Siria, imprimiéndole a la región un carácter aún más convulso e inestable.

Palabras clave: Primavera Árabe - Fuerzas Profundas - MENA - Mundo árabe

\begin{abstract}
The Arab Spring has been a transnational process that affected the Arab countries, scattered throughout the Middle East and the North Africa region (MENA). Despite the hopes that were encrypted with the awakening of societies, the uncertainties that surrounded this process were crystallized in the presence of deep forces that have been operating in the region.

In this sense, this article seeks to analyze in the context of the MENA the configuration of two profound forces in the post-Arab Spring, as well as to identify the actors involved in their actions and interests. They are the return of authoritarianism and the identification of all political Islam as an enemy.

Although these forces are interrelated, for methodological purposes they are analyzed separately, according to how they developed along the decade and how they manifested themselves at different times in the regional context of MENA. This allows a better understanding of the open nature of the conflicts that arose in Libya, Yemen and Syria, giving the region an even more convulsive and unstable character.
\end{abstract}

Key words: Arab Spring - DeepForces - MENA - Arab World

TRABAJO RECIBIDO: 16/11/2021 TRABAJO ACEPTADO: 07/12/2021

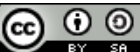

Esta obra está bajo una licencia internacional https://creativecommons.org/licenses/by-sa/4.0/

\footnotetext{
* Doctor en Relaciones Internacionales, Universidad Nacional de Rosario (UNR, Argentina). Director Adjunto del Instituto Rosario de Estudios del Mundo Árabe e Islámico (IREMAI) de la UNR. Docente y Coordinador del Grupo de Estudios del Medio Oriente (GEMO) en la Facultad de Ciencia Política y Relaciones Internacionales (UNR). Correo electrónico: lic rpr@hotmail.com
} 


\section{Introducción}

Tan solo 10 años han trascurrido desde que se inició la Primavera Árabe. Un proceso complejo y dinámico que afectó a la región convulsa del Medio Oriente y Norte de África o MENA -Middle East and North Africa por su acrónimo en inglés- que alteró el status quo en el que hasta ese entonces se encontraba el Mundo árabe. En mayor o menor grado, todos los países que lo integran se vieron afectados tanto en el ámbito doméstico como regional por una serie de cambios, en algunos casos sin precedentes, cuyas consecuencias aún persisten. No ha sido casual el empleo de la palabra 'despertar' para dar cuenta de cómo las respectivas sociedades civiles salieron del estado de letargo a través de las protestas y movilizaciones populares pacíficas frente a los respectivos regímenes de gobierno con larga data en el poder.

Si bien para muchos los acontecimientos en Túnez pudieron ser considerados un hecho aislado, éstos reprodujeron el estado generalizado de malestar regional. Desde Túnez, y como una suerte de tsunami, las olas de protestas se extendieron a Egipto, Libia, Yemen, Bahréin, inspirando otras tantas en Argelia, Jordania, Marruecos, Omán y Arabia Saudita. Aunque los ritmos e intensidades variaron de un país a otro, la pérdida del miedo a los regímenes ( $k$ wauf alnizam) y a los aparatos de seguridad (mukharabat), el carácter pacífico de las movilizaciones (silmiya), la toma del espacio público (la Avenida Bourguiba en Túnez, la plaza Tahrir en el Cairo, Sahad al- Taghyir en Saná o Pearl Roundabout en Manama) y el empleo de las tecnologías de información y comunicación (TIC'S) para la convocatoria, le imprimieron un carácter distintivo a las revueltas devenidas en revoluciones en la segunda década del siglo XXI.

En este sentido, la Primavera árabe se transformó en un proceso transnacional, con personas manifestándose en las calles en una docena de países, reclamando por cambios políticos tangibles que dieran respuestas a la frustración, la humillación, la corrupción y la represión física y simbólica en la vida cotidiana. La pérdida del miedo a la represión (alistibdab) frente a toda manifestación pública se hizo en pos de las demandas de cambios tangibles e inmediatos. La calle pasó a convertirse en el espacio vital de los reclamos al poder y el medio de las convocatorias fueron las redes sociales como Facebook, Twitter y Youtube las cuales escaparon a la censura gubernamental en la era de la globalización. La apelación a la apertura política, la dignidad y la libertad se tradujeron en el pedido por la instauración de la democracia a secas y sin adjetivos -liberal, social, árabe o islámica-, bajo un discurso contestatario cristalizado en dos palabras: 'basta' (kifaya) y 'dignidad' (al-karama).

Más allá de las especificidades de cada sociedad, compartían síntomas de cansancio ante las condiciones objetivas de desocupación -que afectó mayoritariamente a la población joven sin expectativas en el futuro-, de inflación y de pobreza que se agravaron como consecuencia de los efectos de la crisis económica mundial desatada en 2008. También compartían la percepción de corrupción estructural de la clase dirigente, de las grandes familias ligadas al poder y la ausencia de libertades reales de los regímenes políticos, independientemente de su naturaleza, republicana o monárquica. La excusa oficial de que el pueblo no estaba preparado para vivir en democracia o que la necesidad de gobiernos fuertes era la mejor alternativa ante la 'amenaza islamista' dejaba de tener un sustento lógico.

No obstante, la efervescencia política de la denominada Primavera afectó de distintas maneras al heterogéneo mundo árabe. Las revueltas devenidas en algunos casos en revoluciones se produjeron en los países con 'regímenes presidencialistas autoritarios de tipo hereditario' y no en los monárquicos. Un dato que no debe pasar desapercibido en el mundo árabe, específicamente en las repúblicas presidencialistas, fue la introducción de una nueva categoría de régimen que ni siquiera Giovanni Sartori en su tipología contempló, el de 'repúblicas hereditarias'. Esa categoría la introdujo Hafez al-Asad en Siria en el año 2000 antes de su muerte, cuando modificó la constitución habilitando la posibilidad de que su hijo Bashar se convierta en el nuevo presidente después de haber gobernado 30 años el país. El ejercicio del 
nepotismo, como práctica, con el 'traspaso del poder del padre a hijo' era el objetivo a emular por el resto de las repúblicas presidencialistas en el mundo árabe y que precisamente fueron las que atravesaron por la Primavera árabe en el MENA (Sadiki, 2009).

En Túnez, Ben Ali con 23 años en el poder se preparaba (previa realización de elecciones manipuladas) para ceder el cargo a su hijo Mohamed o en su defecto a su segunda esposa Leila Trabelsi. En Egipto, Hosni Mubarak con 30 años de gobierno proponía a su hijo Gamal (el cual era resistido por el ejército); en Yemen Ali Abdullah Saleh, con 33 años en la presidencia intentaba una nueva reelección o ceder el puesto a su hijo Ahmed; y en Libia, el Coronel Muamar Gadafi con casi 42 años rigiendo los destinos del país, postulaba a Saif el Islam como su sucesor ${ }^{1}$.

La perpetuación de los regímenes a través de los 'herederos' fue pensada para seguir controlando el poder político y económico. Pero las condiciones económicas y sociales habían cambiado en el mundo árabe. En la fortaleza de éstos estaba su debilidad, porque ejercían la simple 'dominación sin hegemonía' (Chalkraft, 2014). A los ojos de la población, la sucesión a través de los hijos perpetuaba un sistema que se percibía injusto y corrupto, marcando un divorcio profundo entre los gobiernos y las sociedades. A diferencia del panarabismo durante el siglo XX, que sirvió para aglutinar a la población en pos de un proyecto de unidad árabe, las políticas económicas de libre mercado pusieron al desnudo a los respectivos gobiernos, percibidos como carentes de sensibilidad social y preocupados con el control político y económico.

Si bien en el mundo árabe las protestas -estudiantiles- y las huelgas -sindicales- habían aumentado a lo largo de la primera década del siglo XXI, nunca habían puesto en entredicho la naturaleza del poder político reclamando cambios. El malestar económico y la frustración social por las condiciones mencionadas ut supra, contribuyeron a que la "fuerza de los pequeños sucesos" (Rosenau, 1997, p.78), es decir la muerte de Mohamed Bouazizi, despertara la necesidad del cambio. Así, la mecha revolucionaria comenzó con las protestas pacíficas, las cuales fueron reprimidas hasta que finalmente fue un solo grito en las plazas y en las calles que se replicó en un eco ensordecedor, 'el pueblo pide la caída del régimen' (al-sha 'byuridisqat alNizam).

En términos generales, la Primavera árabe puso al descubierto el tipo de sociedades cerradas, marcadas por la falta de integración política -reservada a los respectivos miembros del régimen- y de integración social que excluía a vastos sectores de la sociedad, entre ellos a los jóvenes que en el mundo árabe -fruto del crecimiento demográfico- representaban un $50 \%$ de la población, vivían en zonas urbanas y accedían a los medios de comunicación no tradicionales que escapaban al control de los Estados.

Los manifestantes en su gran mayoría pertenecían a una generación de jóvenes nacidos en la década del 80 's, acostumbrados a vivir siempre bajo un mismo régimen de gobierno, con leyes de emergencia y aparatos de seguridad en las sombras que les cercenaban un bien preciado y escaso como el agua en el mundo árabe, la libertad. Para éstos, la identidad autoritaria que se había construido socialmente durante décadas en la región y a la que sus padres se acostumbraron, les resultaba ajena porque sabían que existía otra cosa y que podían ser los actores protagonistas del cambio. En definitiva, con las protestas se cuestionaba tanto la

\footnotetext{
${ }^{1}$ A modo de ejemplo, el hijo del presidente Mubarak de Egipto, Gamal, no solo era un banquero representante de esa nueva clase económica sino el candidato a suceder al padre en las elecciones de septiembre de 2011. Se estimaba que en los 30 años en el poder la familia Mubarak había amasado una fortuna que iba entre los 30 mil y 70 mil millones de dólares, teniendo en cuenta las inconsistencias de las declaraciones juradas presentadas ante el Organismo de Supervisión Administrativa de Egipto (Goldstone, 2011). Una situación similar ocurría con la segunda esposa del presidente Ben Alí de Túnez, Leila Trabelsi, más conocida como 'la regente de Cartago' quien se había convertido en la mujer más rica del país, con una fortuna valuada en 6.000 millones de dólares, (Hernando de Larramendi, 2011).
} 
'excepcionalidad árabe' como que los regímenes autoritarios fueran sinónimo de 'estabilidad' regional (Korany, 2011; Droz-Vincent, 2014; Lynch, 2016).

La caída de Ben Alí en Túnez, Hosni Mubarak en Egipto, Muamad Gadafi en Libia, Alí Abdalá Saleh en Yemen y el deslizamiento hacia una guerra civil de impacto regional del régimen sirio de Bashar al-Asad, generaron un alto costo para las sociedades que la atravesaron, alterando además el tablero geopolítico y el balance de poder regional. En términos de Balanche (2012), "una revolución no se hace en un día" sino que es producto de diferentes condiciones que se desarrollan en un contexto y con la participación de actores de diferente naturaleza (p.87). Por eso, como bien señala Martín Muñoz (2013), al momento de estallar, en su interior ya se habían desarrollado las 'revoluciones silenciosas', en algún punto desapercibidas, "producto del cambio demográfico, la hiper-urbanización, el acceso a la educación y a las nuevas tecnologías que fueron aportando una conciencia política y ciudadana" (p. 32).

Por eso el miedo se trasladó a los regímenes de gobierno y la toma del espacio público devino crucial como forma de contestación al poder en los distintos países junto a los pedidos de dignidad (Karama), pan (khebz) y libertad (hurryia). De ese modo, se cifraba en lo político el verdadero cambio, a los fines de mejorar la situación económica y social. Sin embargo, con las demandas de democratización y transición democrática subyacía una segunda descolonización para los árabes, o sea, 'la descolonización árabe interna' pero esta vez del autoritarismo (Khader, 2011).

A las claras, el camino que se emprendía era largo y estaba plagado de obstáculos. El invierno autoritario era una idea socialmente compartida en el contexto del MENA que se resistía a dar lugar a la Primavera, especialmente frente a la amenaza de la aparición de una nueva identidad con democracias en el mundo árabe (a lam al-arabia). A pesar de que las manifestaciones fueron pacíficas, los regímenes emplearon distintos medios para sofocarlas, en algunos casos recurrieron a la negociación con los elementos del Estado profundo ( felul) que no habían desaparecido con la renuncia de sus mandatarios, y en otros, al empleo del recurso de la fuerza.

La Revolución de los Jazmines en Túnez, que había inspirado a otras en el mundo árabe, quedaría con el paso del tiempo sola. En otras palabras, una nueva complejidad con equilibrios frágiles fue emergiendo en el MENA y con ella una 'geopolítica oscura', signada por la presencia de "failed states, political chaos, popular revolts, religious extremism, inter-state conflict, foreign rivalries, and military interventions" (Amirahmadi, 2015, p. 93). Así, se sostiene que en la Post Primavera Árabe nuevas Fuerzas Profundas se impondrían marcando los desafíos que se ciernen sobre una región intrínsecamente convulsa, con nuevos conflictos que han permanecido abiertos.

En ese sentido, el presente artículo busca analizar en el contexto del MENA la configuración de dos fuerzas profundas en la post Primavera en el mundo árabe. Para ello, se recurre al concepto de Fuerzas Profundas acuñado por Pierre Renouvin (1990) y Jean Baptiste Duroselle (1974) en el estudio de la Historia de las Relaciones Internacionales, con el objeto de 'aprehender el fenómeno internacional' en todos sus aspectos, situándolo en el tiempo y en espacio. De acuerdo con la definición de Marcel Merle (1978) brindada desde la Sociología de las Relaciones Internacionales, las fuerzas profundas son "factores geográficos, demográficos, fuerzas económicas y financieras, ideologías, [...] contemplados desde el ángulo caracterológico y en relación con el medio circundante" (p.62). A través de ellas, se puede reconstruir el contexto en el que operan y se desenvuelven los elementos materiales e inmateriales que las componen como así también identificar a los actores regionales y extra regionales involucrados con sus acciones e intereses.

Si bien no se pierde de vista que éstas se encuentran interrelacionadas, a los fines metodológicos se las aborda por separado atendiendo a cómo fueron tomando forma en el transcurso de la década y a cómo se manifestaron en diferentes momentos en el contexto regional. La hibridación de ambas fuerzas le imprimió a los nuevos conflictos de Libia, Yemen 
y Siria la particular característica de permanecer abiertos, dotando a la región de un carácter aún más convulso e inestable como las arenas que se encuentran diseminadas en el lugar.

\section{Las Fuerzas profundas en el MENA}

Con posterioridad a la irrupción de la Primavera Árabe, la región del MENA estaba atravesada por la configuración de dos fuerzas profundas: el retorno del autoritarismo, que cobró nuevos bríos con el golpe de estado en 2013 en Egipto y el reconocimiento de todo el Islam Político como enemigo, generando una situación de competencia y rivalidades en la geopolítica regional.

\section{2.a El retorno del autoritarismo}

La primera de las fuerzas profundas es el retorno del status quo, es decir, el regreso del autoritarismo o la estación invernal que caracterizó al mundo árabe. En el fragor de los acontecimientos, fuerzas subterráneas se fueron moviendo con el fin de restaurar el orden perdido. En tal sentido, Egipto no pasaba desapercibido en el contexto regional en virtud que las elecciones libres habían consagrado a los perseguidos de siempre -los Hermanos Musulmanesquienes no solo planteaban cambiar la identidad del país, con la adopción de una democracia árabe con referencia islámica de acuerdo con la nueva constitución, sino que también la erigían como un modelo a emular ${ }^{2}$.

$\mathrm{Al}$ respecto, Masoud (2014) bien señala que:

Where Egypt leads, other Arab countries will (try to) follow. Egypt has long been the cultural and intellectual center of gravity of the Arab world and the stakes of the Egyptian transition are high. If the country manages to become a functioning democracy, one could imagine every election there becoming a focal point for fresh protests in Syria or Saudi Arabia, with the people of each yearning for their own version of democracy that eighty million of the fellow Arabs enjoys. But if Egypt's transition detours into chaos, Islamic extremism, or economic collapse, its neighbors may consider themselves fortunate to dwell under the lugubrious stability furnished by the strongman (p. 246).

Efectivamente, el golpe de estado de julio de 2013 realizado por el general al-Sisi devino en un punto de inflexión en lo que respecta a las expectativas de transición democráticas en el país y en la región. Más allá de los errores propios cometidos en el ejercicio de gobierno por parte del islamista Mohamed Morsi, la revolución llegaba a su fin con la proscripción del partido que lo llevó al poder, la persecución política, el exilio y la represión sobre sus miembros, como así también la prohibición de actuar en la sociedad civil por ser catalogada

\footnotetext{
${ }^{2}$ La Hermandad Musulmana fue un movimiento político religioso creado en 1928 por Hassan al-Banna en Egipto. Su obra ha sido fuente de inspiración en dos sentidos. Por un lado, criticando la Modernidad occidental impuesta desde el exterior por potencias europeas, lo cual condujo al establecimiento de un Estado laico y secular alejado del ideal de Estado Islámico. Proscriptos durante el Nasserismo, y con filiales en varios países, renunciaron en los 70' a la violencia (lo que generó fricciones con los grupos partidarios de la violencia política) y comenzaron a participar en el 2005 en las elecciones parlamentarias en Egipto. Mientras tanto su accionar se dio en la sociedad civil, a través de una reislamización que emprendieron con acciones sociales.

Por el otro, también ha sido una fuente de inspiración para grupos radicalizados extremistas que abrazaron el ideal de un Estado Islámico por la vía revolucionaria o terrorista. Un ejemplo de esto último fue la escisión al interior de la Hermandad Musulmana de la denominada Yihad Islámica que perpetró el magnicidio al entonces presidente Anwar el-Sadat en 1981. Más cercanos en el tiempo, de la Hermandad Musulmana salió Aymán al Zawahiri, actual líder del grupo terrorista Al-Qaeda.
} 
como una organización terrorista. Esta última medida fue secundada por algunas de las monarquías del Golfo -Arabia Saudita, Emiratos Árabes Unidos (EUA) y Kuwait- que brindaron apoyo al nuevo gobierno generando un eje de países que identificaron abiertamente al Islam Político moderado como un enemigo identitario a combatir.

Desde entonces, el juego de alianzas en el mundo árabe sunnita se constituyó en torno a quienes apoyaban o rechazaban a dicha organización con más de ochenta años de existencia y diseminada por diferentes países en el MENA. La vuelta de los Generales en Egipto fue sin más el retorno del autoritarismo, pero en una versión reloaded o 2.0, en donde se había aprendido de los sucesos de la Primavera árabe. Ello no significaba la mejora de las condiciones sociales y económicas que precipitaron las protestas durante 2011, porque como bien sostiene Maya Yahya (2019):

Today, nearly ten yearslater, the situation in the Middle East looks even worse than it did before the Arab Spring. Political repression is more onerous. Economic growth is sluggish and unequal. Corruption remains rampant. Gender is more aspiration than reality (p.49).

Por el contrario, el retorno del autoritarismo redundó en el perfeccionamiento de las acciones represivas y de control sobre los supuestos enemigos, con el empleo de la tecnología cibernética en la dimensión doméstica pero también regional. Antes, el autoritarismo yacía en la ausencia de democracia y en la presencia de un pacto mediante el cual los gobiernos brindaban respuestas a las necesidades de la población a cambio de renunciar a las libertades políticas. El andamiaje legal para restringir las actividades políticas formaba parte del low-intensity coersion que se combinaba perfectamente con el high-intensity coersion a través de la represión física ante cualquier atisbo de disidencia. Primero ésta se ejercía sobre el espacio público vedado para la protesta, y luego, con una batería de medidas que se implementaban a los fines ejemplificadores sobre toda la sociedad, para sembrar el sentimiento propio de un régimen autoritario, el miedo. Entre ellas han sido recurrentes las detenciones arbitrarias, los asesinatos extrajudiciales selectivos y el empleo indiscriminado de la tortura empleando tanto los aparatos civiles como los de policía -de inteligencia y de seguridad-incluidas las unidades especiales de las Fuerzas Armadas (Yom, 2014).

Sin embargo, a partir de 2013, la cooperación regional fue in crescendo entre los Ministerios del Interior, Defensa y agencias con Estrategias de Ciber Seguridad que se crearon en los distintos Estados en la segunda década del siglo XXI. De ese modo, se fue configurando una 'meta dimensión' de la coerción en el ciber espacio marcando una diferencia. Durante la Primavera Árabe el empleo de las TIC's había permitido a los manifestantes auto-organizarse burlando a los aparatos de seguridad, convocando a la toma del espacio público. Desde entonces, han sido los gobiernos, como bien señala Soliman (2020) los que recurrieron al "use of digital information technology by authoritarian regimes to surveil, repress, and manipulate domestic and foreign populations" (p. 124).

El ejemplo más acabado de esto último y de cómo las ciber-tecnologías se emplearon con el fin de manipular, confundir o distorsionar la información se produjo al interior del Consejo de Cooperación del Golfo (CCG) en 2017, generando la crisis diplomática y posterior bloqueo de Qatar. En ese entonces, la Agencia de Noticias de Qatar (QNA, por su sigla en inglés) publicó una información en la que el emir Sheikh Tamimbin Hamad sostenía que 'Irán era una potencia regional que no podía ser ignorada'. Junto al pedido de explicaciones formales a las autoridades qataríes, se empleó la red social de Twitter para desacreditar al gobierno durante semanas. La QNA descubrió con apoyo de los Estados Unidos que se había realizado una operación híbrida -técnicamente denominada info-ops- desde servidores que conducían a EAU con el fin de desprestigiar a Doha y someterla a las decisiones del CCG por brindar apoyo internacional a la Hermandad Musulmana en el MENA.

Así, se puede afirmar que el MENA ingresó al siglo XXI, en la denominada cuarta Revolución Industrial con el empleo de plataformas y de tecnologías cibernéticas con la excusa de combatir el delito y el terrorismo internacional, cuando en realidad ha sido una inversión de 
los Estados en la adquisición de sistemas de vigilancia interna y externa. Estos ya no necesitaban realizar apagones informáticos como ocurrieron en el contexto de la Primavera Árabe en Túnez, Libia, Siria, Egipto para incomunicar a la población, sino utilizarlas para controlar la información que circula en la red y de esa manera evitar nuevos sucesos como los que alteraron el status quo en 2011.

La modernización en esta dimensión ha coincidido con el lanzamiento de las denominadas 'Visiones' -o proyectos- que prevén para los próximos años la diversificación de los sectores productivos con una nueva infraestructura con conectividad $5 \mathrm{G}$ en la dimensión económica ${ }^{3}$. Pero también, con el empleo de sofisticados programas y plataformas digitales sobre disidentes, periodistas, organizaciones no gubernamentales, minorías LGBTQ y población en general en la dimensión securitaria. Por ejemplo, en plena crisis del COVID-19 a las cuarentenas, toques de queda, prohibición de reuniones sociales y restablecimiento de leyes de emergencia se les sumaron el uso de la tecnología biométrica, la geolocalización y las APP's con supuestos fines sanitarios, vulnerando los derechos humanos. De acuerdo con Khamis (2020), se produjo un ciber control,

Namely reliance on online surveillance and contact tracing tools and applications, which are justified by regimes as part of the effort to curb the spread of the deadly pandemic, but which simultaneously, and dangerously, open the door to threats to personal security, invasion of privacy, and government hacking of opposition (p.146).

Si bien la pandemia exteriorizó las capacidades cibernéticas alcanzadas, ya existían denuncias de ONG como Amnesty International y de centros de investigaciones que velan por los derechos humanos digitales como Citizen Lab, Lookout Security y Privacy International. Todas ellas alertaban sobre el peligro de la vigilancia y el control que países árabes -como EAU, Bahréin, Marruecos y Arabia Saudita- realizaban sobre la población con tecnología de origen israelí en sus propios países y en el exterior. Precisamente los tres primeros países fueron los que normalizaron las relaciones a mediados de 2020 con los Acuerdos de Abraham, destacándose la cooperación pública y privada en esta meta dimensión. Por su parte, el reino saudita continuó manteniendo una 'alianza tácita' con Israel y una cooperación comercial con empresas israelíes entre la que se destaca la cuestionada NSO-Group ${ }^{4}$.

La cibertecnología ha permitido obtener lo que se considera el elemento más perecedero, la información, y que cada ciudadano con el empleo de APP's en móviles y tablets suministra todo el tiempo, las 24 horas. De allí que ésta resulte vital porque ha permitido a las autoridades pasar a la dimensión cinética (física o real) con la high-intensity coersion cuando identifica, detiene, reprime o acalla las voces disidentes, en general, aplicando leyes antiterroristas (low-intensity coersion).

En el mundo árabe, EAU lleva adelante el megaproyecto de vigilancia conocido como Falcon Eye, el cual ha sido emulado por Bahréin. A través del despliegue de cámaras en las calles, registros de llamadas y control de voz de los dispositivos móviles, cada ciudadano

\footnotetext{
${ }^{3}$ En el transcurso de la última década, varios países han presentado proyectos de mediano plazo tendientes a diversificar los sectores económicos. Entre ellos se destacan la Visión 2030 de Arabia Saudita, la Visión 2035 de EAU o la Visión 2025 de Marruecos. Asimismo, Egipto inició mega proyectos faraónicos, como la construcción de una nueva capital a $40 \mathrm{~km}$ del Cairo, la ampliación del canal de Suez conectado con nuevos puertos y aeropuertos como así también una obra de reconversión de tierras áridas en el desierto de Feddam.

${ }^{4}$ El periodista saudí Jamal Khashoggi-asesinado en el consulado de Turquía- y el activista de Derechos Humanos (DDHH) Omar Abdulaziz con residencia en Canadá fueron espiados durante 2018 con un potente malware espía de la empresa NSO-Group de origen israelí, conocido como Pegasus. La empresa NSO-Group -creada en 2010 por Omri Lavie y Shalev Hulio y valuada en mil millones de dólares- se ha defendido de las acusaciones internacionales aduciendo que solo vende tecnología de ciberseguridad a gobiernos para la lucha en contra del terrorismo y del crimen organizado. Sin embargo, nunca presentó una lista de sus clientes ni ha desmentido que su tecnología haya sido utilizada para vigilar a las poblaciones en los países árabes.
} 
termina llevando un espía en el bolsillo. La pregunta que se impone es quiénes son los actores que suministran este tipo de tecnología que permite profundizar el autoritarismo en los países árabes. La respuesta en parte se respondió con relación a Israel que se ha constituido en la principal ciberpotencia del MENA (Paredes Rodríguez, 2021).

Pero también potencias extra regionales sin pergaminos democráticos han vendido sofisticados sistemas de vigilancia ciudadana. Por un lado, se encuentra Rusia que exportó a través de empresas nacionales -como Proteiy Peter-Service- el System for Operative Investigative Activities (SORM) a las empresas de telecomunicaciones de Irak, Bahréin y Qatar para interceptar y controlar todas las comunicaciones en el país (Morgus, 2018, p. 86). Por otro lado, se encuentra China que exportó a EAU tecnología de reconocimiento facial a través de cámaras desplegadas por todo el territorio para implementar la política de seguridad conocida como Police Withou tPolicemen (policía sin policías) que se considera un sistema revolucionario de vigilancia sobre la población (Polyakova y Meserole, 2019, p. 6).

En otras palabras, esto ha dado lugar a que se erijan Estados 'ciberautoritarios', con un poder que dejó de estar en la gente de a pie (como ocurrió en 2011) para pasar a ser un monopolio exclusivo de los Estados. A diez años de la Primavera Árabe, estos han logrado evitar -como sostiene Bordón Osorio (2020) "las amenazas al modelo de estabilidad política y paz social definido por los regímenes".

\section{2.b El Islam Político como enemigo}

La segunda fuerza que atraviesa la región del MENA y que permite entender la composición y naturaleza de las alianzas ha sido la identificación de todo el Islam Político como enemigo. Si bien este no es un fenómeno monolítico y presenta varios rostros se visualiza "como una forma de instrumentalización del Islam (religión) por individuos, grupos y organizaciones que persiguen fines políticos" (Denoeux, 2002, p. 61).

Por un lado, se encuentra el Islam político en la versión salafista radical que plantea el regreso a los años de esplendor de la civilización islámica y el empleo de la Yihad -que en términos etimológicos significa esfuerzo- como sexto pilar de la religión islámica ${ }^{5}$. En tal sentido, la interpreta como una 'Guerra Santa' contra los agresores e infieles en el que se legitima el recurso de la violencia o la fuerza en todas sus formas ${ }^{6}$. Pero por el otro, se encuentra un Islam político moderado y más extendido geográficamente que renunció a la violencia como medio para alcanzar sus objetivos políticos y se abocó a denunciar e impugnar a los regímenes autoritarios.

\footnotetext{
${ }^{5}$ Etimológicamente, Islam significa entrega. Por ende, toda persona que se precie de ser islámica es la que se entrega a Allah y cumple con los cinco pilares (arkan al-Islam ) que el Profeta Mahoma dio a conocer a los hombres: $1^{\circ}$ La Shahada: entendida como el acto de fe más sublime que consiste en decir con convicción que Allah es el único Dios, y Mahoma es su profeta; $2^{\circ}$ cumplir con el Salat, es decir con las oraciones diarias que dependiendo de los países pueden ser hasta cinco, en dirección hacia la Meca, en un claro signo de postración y reconocimiento ante el único Dios; $3^{\circ}$ el Sawm, que implica realizar el ayuno durante el mes sagrado del Ramadán desde el alba hasta la caída del sol, en claro signo de solidaridad con este sacrificio de los que menos tienen, es decir los desprotegidos; $4^{\circ}$ el Hajj, o sea la peregrinación que por lo menos una vez en la vida todo islámico entregado a Allah debe realizar hacia la Meca en donde se encuentra la Kaaba (lugar de promesa y reconciliación de Dios con los hombres); y $5^{\circ}$ cumplir con el Zaqat, es decir con la limosna que se debe depositar en las mezquitas con el fin de lograr la justicia social en la comunidad porque se orienta a los que menos tienen.

${ }^{6}$ El Islam Político radical tiene como uno de los principales ideólogos a Sayid Qutb, quien fuera en sus años de juventud miembro de la Hermandad Musulmana. En sus últimos años de vida en la cárcel renunció a la moderación para convertirse en uno de los principales exponentes de la instrumentalización del Islam a través de la violencia. Su pensamiento ha inspirado la creación de la Yihad Islamiya, alJama'a al-Islamiyya o Al-qaeda, Ansar-al-Islam entre otros.
} 
Durante décadas la 'excepcionalidad árabe' se había sustentado, entre otras cuestiones, en la noción de estabilidad que los regímenes autoritarios detentaban en calidad de reaseguro frente a la temida amenaza islamista. La percepción de amenaza no solo provenía del Islam político radical que hasta la Primavera Árabe encarnaba en gran medida Al-Qaeda. Por el contrario, la apertura de los sistemas políticos post 2011 hacía prever que el Islam político moderado de la Hermandad Musulmana podía imponerse al ser ésta el actor mejor posicionado gracias a la labor social ininterrumpida (Paredes Rodríguez, 2018).

Sin embargo, la maduración del cambio ideológico como elemento inmaterial gestado durante años por dicha organización se constituía en una amenaza al status quo autoritario por conjugar democracia con Islam en el mundo árabe. De acuerdo con Katulis (2015)

Hay tendencias muy diversas dentro del pensamiento islamista, desde las voces más radicales como el EIIL y Al Qaeda, hasta las más moderadas, como los grupos islamistas que participan en los procesos políticos democráticos de países como Túnez (p. 26).

Así lo referenciaba la llegada al poder del partido islamista Ennahda en Túnez y de la Libertad y la Justicia en Egipto y Marruecos, sumado a la presencia de filiales en Jordania, Siria, Gaza y Turquía. A excepción de Qatar, las monarquías del Golfo dieron la bienvenida al golpe de estado en Egipto que puso fin a un anatema identitario de democracia árabe islámica. En consecuencia, de un lado quedaron los países en los que tiene presencia la organización, y del otro, aquellos que no distinguen entre la moderación y el uso de la fuerza en virtud de que sólo representa una amenaza a la que acusan de terrorista.

Para estos últimos, no hay distingos entre los hermanos musulmanes y Al-Qaeda o el propio Estado Islámico, porque simplemente son enemigos a combatir a través de la proscripción, la cooperación interestatal en seguridad y el uso de la fuerza de forma unilateral o por medio de coaliciones regionales. Declarar a todo el Islam político como terrorista ha sido funcional a los intereses de determinados Estados, ya sea para evitar una impugnación a la legitimidad política interna como para encontrar apoyo internacional en la lucha contra el terrorismo mediante acciones represivas sobre la propia población o en el exterior.

Con relación a esto último, a partir de 2013 se produjo una militarización de la Primavera Árabe y con ello un nuevo capítulo se comenzó a escribir. El accionar militar de Egipto junto a Emiratos Árabes Unidos en el conflicto de Libia, favoreciendo al general Jalifa Haftar - contrario al Gobierno de Unidad Nacional reconocido internacionalmente- respondió a que se encontraba integrado por miembros de la Hermandad Musulmana libia ${ }^{7}$. Asimismo, el apoyo logístico y militar de EAU junto a Arabia Saudita al Ejército de Liberación Sirio (ELS) y luego al Frente Islámico Sirio (FIS) en contra del Consejo Nacional Sirio (CNS) ${ }^{8}$-considerado el gobierno internacionalmente legítimo en el exilio- corroboraba la identificación y composición de las alianzas en contra de todo elemento relacionado con el Islam Político moderado y su posibilidad de devenir en gobierno (Droz-Vincet, 2018; Lynch, 2016; Yahya, 2019).

Mientras el islamismo moderado comenzó a atravesar sus horas bajas, el islamismo radical cobró nuevos bríos con la aparición de Estado Islámico en 2014, lo cual significó una nueva amenaza a la seguridad regional e internacional. El anuncio del establecimiento de un Califato con el autoproclamado califa Abú Bakr al Baghdadi sobre los territorios de Siria e Irak, no solo impugnaba las fronteras heredadas por la pluma europea que había creado el sistema de Estados nacionales donde antes no los había en el Imperio otomano. Sino que, además, venía a

\footnotetext{
${ }^{7}$ Qatar con apoyo de Turquía ha intervenido en el conflicto libio en favor del gobierno reconocido por la comunidad internacional. A estos se les sumaron las Naciones Unidas y dentro de la Unión Europea, Italia.

${ }^{8}$ Entre las filas del CNS se encontraban miembros de la Hermandad Musulmana Siria perseguida durante décadas en el país.
} 
complejizar aún más el escenario regional con la aparición de un nuevo actor no estatal que llamaba a 'permanecer y expandirse" .

A diferencia de Al-Qaeda que apelaba a una Yihad Global con el objeto de conformar un Califato mundial, Estado Islámico buscó un anclaje territorial en donde instrumentalizar la religión con fines políticos. De allí que su Yihad sea catalogada como híbrida, por incluir un discurso ideológico imbuido en la religión con una agenda política y social en terreno (Refslund Hamming, 2019).

Si bien esto dio lugar a una competencia intrajihadista -en lo que se podría denominar la batalla por las mentes a la hora de conseguir nuevos seguidores- ambas organizaciones coincidieron en la descentralización operativa para no ser derrotadas ${ }^{10}$. Los combates emprendidos por la Coalición Internacional entre 2014 y 2018 redujeron al Estado Islámico a su práctica desintegración territorial, aunque "conserva su imperio digital" (Kaush, 2018, p. 111). Esto se ha traducido en operaciones en la webcon el fin de reclutar adeptos, adoctrinar con sus revistas -Dabiq y Rumiyah- y realizar hackeos sobre infraestructura y medios occidentales.

Empero, su ideología ha pervivido entre sus seguidores, con células diseminadas por distintos países -en el desierto de Siria y en el Norte de Irak- como así también en el Sudeste asiático y recientemente en Afganistán con la aparición del Estado Islámico de Khorasan, rivalizando con el régimen Talibán.

Para países como Arabia Saudita, Egipto, Jordania, Kuwait y EAU el Islam político moderado ha sido una amenaza a una identidad socialmente compartida en el MENA, de allí su empeño por restituir el status quo autoritario alterado por la Primavera árabe. Sin embargo, por los conflictos que se fueron abriendo, actores no estatales que encarnan el Islam político radical han devenido también en una amenaza existencial. No solo por considerar apóstata al régimen de la familia Saud, que custodia dos de los santos lugares para la religión islámica (la Meca y Medina), sino también por las células dormidas o lobos solitarios que han retornado a sus respectivos países de origen con el know how adquirido en el escenario sirio. La amenaza islamista ha dejado de ser un fantasma para convertirse en una realidad, por eso las nuevas tecnologías son empleadas en un sentido securitario.

\section{La persistencia de los conflictos abiertos}

A los denominados 'viejos conflictos' que durante décadas marcaron la agenda regional e internacional -como el palestino-israelí- se sumaron otros nuevos, una vez desencadenada la Primavera árabe. Las dos fuerzas profundas abordadas en el apartado anterior se manifestaron en ellos, imprimiéndole un mayor carácter convulso a la región, desde el momento que han tenido la particularidad de permanecer abiertos. Así, las propias dinámicas regionales con los intereses, las alianzas y las continuas penetraciones externas, han contribuido para que éstos no encuentren una solución definitiva en el transcurso del tiempo.

En este punto, se identifican tres escenarios de conflictividad que permanecen abiertos. Libia, Yemen y Siria, los cuales han concitado la atención internacional a lo largo de la década dependiendo del recrudecimiento de la violencia, la fragmentación territorial, los actores involucrados, incluidos los externos, que hicieron de estos una proxy war -o guerra por delegación- y las conversaciones tendientes para su resolución ${ }^{11}$. El retorno del status quo

\footnotetext{
${ }^{9}$ Estado Islámico logró ocupar 215 mil $\mathrm{Km} 2$ con 6 millones de personas en su interior y declaró la incorporación de wilayas (provincias externas) como la Península del Sinaí (Egipto) y el desierto de Fezzan (Libia).

${ }^{10}$ La descentralización táctica de al-Qaeda generó extensiones geográficas tales como: al-Qaeda central, al-Qaeda en el Magreb, al-Qaeda en la península Arábiga.

${ }^{11}$ Una proxy war es un conflicto en el que terceros actores intervienen de manera indirecta, brindando apoyo directo o indirecto a uno de los actores en combate, con el objetivo de alcanzar un resultado
} 
autoritario y la condena del Islam político moderado operaron en los escenarios haciendo explícitas las rivalidades y la competencia de actores regionales y extra regionales como se podrá ver a continuación.

En el primer escenario se encuentra Libia, un país donde la esperanza cifrada en la caída del Coronel Gaddafi dio lugar a un vacío de poder, en el cual no sólo había que reconstruir las instituciones sino también el propio Estado, con una identidad nacional dividida en tribus. El caso libio tuvo una particularidad, el Consejo de Seguridad de Naciones Unidas a través de la Res. 1973 habilitó el establecimiento de una Zona de Exclusión Aérea (ZEA) para que las fuerzas regulares no hicieran uso de la aviación y así proteger a la población de Bengasi, lugar donde habían comenzado las protestas. De ese modo, la Organización del Tratado del Atlántico Norte (OTAN) a través de los socios europeos se encargó de las operaciones posibilitando a los rebeldes llegar a Trípoli, la capital administrativa del país ${ }^{12}$. Con ocho meses de duración, la Revolución del 17 de febrero llegaba a su fin inaugurando una nueva etapa política.

La presencia de milicias armadas enfrentándose por todo el país polarizó a los actores políticos entre el Congreso General Nacional (CGN) ${ }^{13}$-con integrantes de la Hermandad Musulmana- en Trípoli al Oeste del país, y el Ejército Nacional Libio (ENL) en la Cirenaica en el Este. El caos y partición de Libia en tres zonas, dos con sus respectivas autoridades recibiendo apoyo de distintos actores regionales e internacionales enfrentándose en una guerra de desgaste entre 2011 y 2013 se le sumó una tercera ubicada en el desierto de Fezzan. Las fronteras sur lindantes con el desierto subsahariano se constituyeron en un agujero negro donde la comunidad internacional hace silencio y en el que proliferan el crimen organizado, la trata de personas y la presencia de células terroristas -entre ellas la wilaya del Estado Islámicoconcitando una mayor inestabilidad regional.

Tras el golpe de 2013 en Egipto, y en coincidencia con la nueva etapa de la Primavera Árabe, el General Haftar emprendió desde el Oriente la Operación Dignidad con la excusa de purgar el país de los elementos islamistas (moderados y radicalizados) y de unificar el gobierno bajo su poder. Para ello contó con el apoyo externo del gobierno egipcio del general Al-sisi, EAU, Arabia Saudita, Francia y Rusia. Desde Trípoli, se conformó el Acuerdo de Gobierno Nacional (AGN) a cargo del Presidente Fayedal-Serraj, quien cerró filas para detenerlo con el apoyo de la Unión Europea, Turquía y Qatar.

De acuerdo con Lombardi y Medín (2021), a la división entre el AGN y la Cámara de Representantes (CR) instalada en la ciudad de Tobruk, sumada a la oposición militar del ENL se agregó la presencia de actores regionales que contribuyeron a que se produzca un escenario de proxy war marcado por:

la injerencia externa que operó a través de la provisión de recursos financieros y armamentos avanzados a los aliados locales; el uso extendido de drones armados; la contratación de milicias externas y empresas privadas militares -léase mercenarios-, principalmente de origen ruso, sirio, sudanés y chadiano, así como campañas de desinformación mediante la utilización de fakenews en redes sociales (p.73).

A pesar de las conferencias internacionales que se celebraron para encauzar el diálogo y terminar con el conflicto libio, la nueva etapa en la que ingresó la guerra entre 2015 y 2020 se vio afectada por la irrupción del COVID-19, lo que precipitó ensayar una salida entre los propios actores nacionales. Por un lado, mientras la comunidad internacional estaba abocada a

\footnotetext{
favorable a sus preferencias estratégicas (Mumford, 2013).

${ }^{12}$ La administración norteamericana de Barak Obama aplicó un supuesto de la política exterior 'leading behind the lines' en el que buscó que fueran los socios de la organización atlántica los que realicen las operaciones, evitando no repetir los casos de Irak y Afganistán. Por su parte, Rusia y China consideraron un despropósito la interpretación que se hizo de la Res. 1973, motivo por el cual vetaron cualquier resolución en los otros conflictos, por ejemplo el sirio.

${ }^{13}$ El objetivo del CGN era redactar una constitución nacional que consagre un sistema político inclusivo basado en la democracia, la cual no contó con el apoyo de todas las fuerzas políticas.
} 
enfrentar la pandemia, el General Haftar intentó realizar un golpe de estado sobre el gobierno de Trípoli en el mes de marzo de 2020, el cual fue repelido gracias a la ayuda de drones autónomos de origen turco, según lo denunciaron las Naciones Unidas $(2021)^{14}$. Esto puso de manifiesto que la cibertecnología también se empleaba en los conflictos, pero con la particularidad de contar con el sello del made in regional. ${ }^{15}$

Por el otro, y con mayor éxito estuvo la iniciativa del presidente del AGN Serraj de declarar unilateralmente el cese de las hostilidades el 20 de agosto de 2020, a la que se plegó también unos días después la CR. Dicha iniciativa contó con el apoyo de Naciones Unidas, que emprendió el Foro de Diálogo Político Libio con una Hoja de Ruta en la que se contempló la elección de autoridades nacionales interinas y el llamado a comicios generales programadas para el 24 de diciembre de 2021.

El 5 de febrero de 2021 se eligió a Mohamed Yunis Al-Menfi en el cargo de Presidente y a Abdul Hamid Dbeiba como primer ministro del Gobierno de Unidad Nacional. Ambos se comprometieron en alcanzar la reconciliación nacional, la reunificación de instituciones, la reactivación económica, la reconstrucción del país, y a mantener la convocatoria a elecciones nacionales de diciembre. El interrogante es saber qué hará el general Haftar, dado que tomó licencia para presentarse a las elecciones. Sin embargo, en el caso de perder se desconoce si aceptará los resultados o volverá a impedir la transición hacia una democracia genuina.

En el segundo escenario se encuentra el país que ha descendido al peor de los infiernos, Yemen. A las condiciones estructurales adversas que atraviesa por ser el país más pobre del mundo árabe, se sumó por un lado la internacionalización del conflicto a partir de 2015, donde los actores locales reciben el apoyo de manera directa o indirecta de las potencias regionales que dirimen sus intereses en el terreno en lo que se considera una proxy war. Y por el otro, a la crisis humanitaria que atraviesa la población se adicionó la situación sanitaria producto del COVID-19, exponiendo la vulnerabilidad de la infraestructura devastada y del sistema sanitario colapsado, que requiere de la ayuda internacional para atender las necesidades urgentes de la población.

Los sucesos de la Primavera Árabe pusieron fin al gobierno de Ali Abdalá Saleh, pero dejaron al descubierto las líneas de fracturas que atraviesan el país. Entre ellas la división entre el Norte y el Sur que nunca se zanjó a pesar de su unificación en 1990, la presencia de la extensión geográfica de al-Qaeda en la Península Arábiga y la composición atomizada y tribal de su sociedad.

En 2015, la minoría houti del Norte derrocó al presidente Abd Rabbuh Mansur al-Hadi tomando la capital, Saná. Desde entonces, el conflicto entre actores locales se internacionalizó, deviniendo también en una proxy war. En este caso, el príncipe heredero de Arabia Saudita veía que atrás del avance houti se encontraba la República Islámica de Irán, lo cual motivó la creación de una coalición internacional integrada por EAU, Qatar, Kuwait, Bahréin, Egipto, Marruecos, Jordania y Sudán ${ }^{16}$. La operación militar bautizada Decisive Storm buscó hacer retroceder a los houtíes con un bombardeo constante y un bloqueo naval que agravó la crisis humanitaria. Pero su prolongación en el tiempo además puso al descubierto las diferentes posiciones de los integrantes de la coalición.

\footnotetext{
${ }^{14}$ En la contraofensiva del presidente Serraj se emplearon vehículos aéreos de combate no tripulados o como el STM Kargu-2 de origen turco.

${ }^{15}$ Hasta ese entonces, los Estados Unidos se había caracterizado por el emplear drones en la lucha contra el terrorismo internacional en la región del MENA, interceptando y asesinando a líderes de al-Qaeda y del Estado Islámico, como por ejemplo el auto proclamado califa Baghdadi.

${ }^{16}$ Cabe mencionar que Irán capitalizó el conflicto yemení a la hora de ganar en los houtíes un aliado proxy. Sin embargo, ha desmentido oficialmente tener una participación directa. Es por ello que su intervención ha sido a través de ventas de armas, apoyo logístico con el uso de drones y asistencia económica.
} 
En primer lugar, la crisis diplomática de 2017 desatada con Qatar fracturó al CCG, dado que se la acusaba no sólo de reconocer a Irán como potencia regional sino también de brindar apoyo a las filiales de la Hermandad Musulmana en el MENA. En segundo lugar, quien fuera el principal aliado del reino saudita, EAU, se opuso a seguir brindado ayuda a Hadi en virtud de que el partido al-islah en el que se apoya, pertenece a la rama yemení de la Hermandad Musulmana. En consecuencia, las desavenencias se tornaron explícitas con Arabia Saudita cuando dejó de respaldarlo para pasar a apoyar al movimiento independentista del Sur (Soler I Lecha, 2018; Saione y Foyth, 2021).

Ante la falta de perspectivas para poner fin al conflicto, Yemen ha sido noticia por la grave crisis humanitaria que atravesó en un contexto de COVID-19. El llamado del Secretario General de las Naciones Unidas Antonio Gûterres para detener los combates fue con un sentido humanitario urgente. De acuerdo con la ONG OXFAM, 12 mil civiles perdieron la vida por el conflicto, 4 millones se convirtieron en desplazados, el $80 \%$ de la población carece de alimentos y necesita de la ayuda internacional que no llega por el bloqueo de la coalición. En condiciones sanitarias alarmantes conviven enfermedades endémicas como el cólera, la difteria y la polio. A ello se suma que el $99 \%$ de la población no se ha vacunado y la tasa de mortalidad por COVID-19 ha aumentado un $420 \%$ (OXFAM, 2020).

La prolongación a lo largo de seis años de la intervención militar y las divisiones al interior de la coalición, condujeron a Arabia Saudita a presentar en marzo de 2021 un alto el fuego ${ }^{17}$. Sin embargo, éste fue rechazado por los houtíes por considerarlo insuficiente desde el momento que no se levantó el bloqueo impuesto. Así, el conflicto yemení devino en un laberinto del que no se ha podido salir y en el que se requiere de un compromiso serio de la comunidad internacional y de la región del MENA en su conjunto.

En una situación parecida, pero con características distintivas, se encuentra el tercer escenario: Siria. Un país destruido por los diez años de conflicto entre el régimen y la multiplicidad de actores que conforman la oposición, sumado a la intervención de potencias externas -Estados Unidos y Rusia- y de potencias regionales -Arabia Saudita, Irán y Turquía- en un sinuoso juego de alianzas. A la fragmentación del territorio en áreas de influencia, el auge y ocaso del Estado Islámico (no así su desaparición) el régimen gobernante ha sido el único que sorteó la Primavera árabe permaneciendo en el poder.

Cuando el 15 de marzo de 2011 comenzaron las protestas pacíficas en la ciudad de Deraa, el régimen baasista de Bashar al-Asad emuló a Libia al emplear la fuerza militar para reprimir las protestas. En ese entonces, con el fin de granjearse el apoyo internacional, adujo estar luchando en contra de infiltrados terroristas que buscaban desestabilizar el país. Sin embargo, en la región solo la República Islámica de Irán le brindó su apoyo incondicional, con el despliegue de efectivos de la Guardia Republicana en el terreno junto a las Brigadas de la Noche, el brazo armado de Hezbollah del Líbano. En el mundo árabe el país quedó virtualmente aislado, cuando el 11 de noviembre de 2011 la Liga Árabe lo suspendió por la represión y la violación de los derechos humanos sobre la propia población siria.

Sin embargo, ese contexto habilitó a que varios países comenzaran a disputarse el futuro de una Siria post al-Asad, apoyando a distintos actores, poniendo de manifiesto una clara división en el mundo árabe. La estrategia de al-Asad fue la de militarizar las acciones para lo cual necesitaba radicalizar las protestas. Para ello, emitió una amnistía en la que liberó a terroristas jihadistas que pasaron a integrar los distintos grupos que conformaban la oposición (Álvarez-Ossorio, 2016; Karbalan, 2020) Ésta estaba integrada por una miríada de actores dispersos geográficamente en el terreno lo que terminó siendo funcional a la estrategia del gobierno, en virtud de que ninguno pudo alcanzar la preponderancia por sobre el régimen que se mantuvo cohesionado. El CNS o gobierno en el exilio planteaba la creación de un Estado civil, plural y democrático en consonancia con el pensamiento del Islam Político moderado de la

\footnotetext{
${ }^{17}$ Los houtíes no sólo continuaron reteniendo el terreno sino que además desplegaron un accionar que se perfeccionó con el uso de misiles impactando sobre Arabia Saudita, sumado al empleo de drones que le dio una mayor capacidad estratégica.
} 
Hermandad Musulmana egipcia; el ELS in situ abogaba por un Estado libre y democrático viviendo en paz y en libertad y el FIS planteaba reconstruir Siria bajo el Islam apelando a una solución militar no negociada.

En ese contexto, el régimen emprendió acciones en distintos frentes, incluido el cibernético, con la creación del Ejército Electrónico Sirio (SEA, en sus siglas en inglés) a través del cual hackeó diferentes cuentas de twitter y realizó ataques a medios occidentales acusados de esparcir falsas noticias como The Washington Post, Financial Times, la cadena estadounidense CNN y la BBC de Londres. En el MENA atacó el sitio web del medio Qatarí de Al-Jazeera, acusado de diseminar noticias falsas y de promover el pensamiento de la Hermandad Musulmana.

Con la irrupción de Estado Islámico en 2014 y el empleo de armas químicas por parte del régimen en repetidas oportunidades, Rusia no solo lo blindaría diplomáticamente, sino que comenzaría a operar en el terreno en su favor ${ }^{18}$. Al igual que en Libia y en Yemen, Siria se deslizó hacia un escenario de proxy war en el que Turquía pasó de condenar al régimen a apoyar las acciones rusas; Estados Unidos se centró en atacar al Estado Islámico con apoyo del CCG y la comunidad internacional, para luego anunciar el fin de los ataques y la retirada del territorio. E Irán junto a Rusia se concentraron en apoyar el régimen en contra de la oposición y así recuperar las $2 / 3$ partes del territorio.

A las víctimas, heridos y desaparecidos durante el conflicto sirio, se agregó la mayor crisis de refugiados de la historia después de la II Guerra Mundial, con 5.6 millones de refugiados y 6.2 millones de desplazados (Yahya, 2019, p. 52). Situación que se agravó en un contexto del COVID-19 ante la destrucción de la infraestructura sanitaria, el hacinamiento en los campos de refugiados y la ausencia de insumos tales como los servicios básicos de electricidad y de agua potable.

Pese a ello, en 2021 se comenzó a divisar una política de hechos consumados en la que países árabes como Egipto, EAU, Jordania y Bahréin han buscado restablecer los vínculos con Damasco y a negociar el retorno de Siria a la Liga Árabe. La nueva apuesta es atraerlo al mundo árabe sunita, teniendo en cuenta que a pesar de ser el régimen gobernante alawita -cercano al shiísmo- mantiene una posición tradicional contraria al Islam político moderado de la Hermandad Musulmana. De ese modo:

en su palacio en el monte Qasioun que domina Damasco, Bashar al-Asad puede respirar. Cree que lo más difícil ya pasó. Gobierna, es cierto, un país (en realidad, dos tercios del territorio) en bancarrota, parcialmente en ruinas, y se volvió dependiente de sus aliados, Irán y Rusia. Pero sobrevivió, al igual que su régimen. Y ahora el mundo árabe -incluidos los traidores que no lograron derrocarlo- vuelve a tomar el camino de Damasco (Loos, 2021).

En ese contexto, a la comunidad internacional le tocará no sólo la tarea de reconstruir el país y hallar una solución a la crisis de los refugiados y desplazados internos, sino también desplegar una alta ingeniería diplomática para un presidente que se ha erigido como victorioso, pero sobre el cual pesan denuncias de crímenes de Guerra y Crímenes de lesa humanidad en la Corte Penal Internacional.

\section{Conclusiones}

La segunda década del siglo XXI no será recordada por la construcción y el fortalecimiento de los sistemas democráticos en el mundo árabe. Por el contrario, los diez años que transcurrieron desde el inicio del proceso transnacional conocido como Primavera Árabe

\footnotetext{
${ }^{18}$ Los intereses de Rusia en Siria provienen de la Guerra Fría cuando logró una salida a aguas calientes en el Mediterráneo con el puerto de Tartus y con la base aérea de Latakia. La continuidad del gobierno de alAsad se constituyó en una de las principales preocupaciones, las cuales quedaron de manifiesto en la Conferencia de Astaná y en las conversaciones de Sochi.
} 
estuvieron marcados por la configuración de dos fuerzas profundas que recorrieron el MENA. $\mathrm{Su}$ identificación nos ha permitido aprehender el 'fenómeno internacional' con sus nuevos aspectos en el tiempo y el espacio. Así también observar cómo operaron y se imbricaron in situ, especialmente en los nuevos conflictos acaecidos en una de las regiones más convulsas del sistema internacional.

A las claras, el retorno al status quo autoritario en el mundo árabe significó la vuelta a un orden basado en un patrón de conducta amigo/enemigo, en el que las afinidades ideológicas y las alianzas estuvieron marcadas en torno a la identificación de todo el Islam Político como enemigo. Pero también en un perfeccionamiento del autoritarismo acorde a los tiempos que corren y al desarrollo de las nuevas tecnologías. Precisamente éstas dejaron de ser los canales de expresión como oportunamente ocurrió en los albores de la Primavera Árabe, en virtud de que se convirtieron en un mecanismo de control y vigilancia en manos de los Estados. El objetivo buscado ha sido no repetir esos sucesos que alteraron la estabilidad y el orden tratando de borrar todo vestigio de las manifestaciones dela historia reciente. Los niveles de sofisticación de la vigilancia han logrado acallar las voces disidentes, y en pleno contexto de COVID-19, reforzar el control sobre las poblaciones penetrando en la intimidad de la vida privada.

No se puede perder de vista que la combinación de elementos materiales e inmateriales fueron tomando forma a través de dichas fuerzas en la dimensión doméstica y regional. Así, la competencia por la hegemonía y las rivalidades sectarias estuvieron presentes. Estas últimas fueron propiciadas por actores estatales -y no estatales-que han instrumentalizado la religión a la hora de establecer alianzas, perseguir intereses -muchas veces contrapuestos- e involucrarse en los tres conflictos mencionados ut supra que poseen la cualidad de permanecer abiertos. Sin más, el resultado ha sido la presencia de Estados colapsados o fallidos en los que se requiere ingentes sumas de dinero y de ayuda internacional para su reconstrucción. Esta situación ha puesto al descubierto no solo la división existente al interior del mundo árabe para el denominado día después, sino también el drama humanitario, la cara oculta, a la que los pueblos fueron sometidos a la espera de una resolución de los conflictos.

A ello se sumó una característica que se cierne sobre la región y que ha sido la tradicional penetración externa. Si bien no es nueva y se pueden rastrear innumerables antecedentes a lo largo de la historia, el MENA no ha dejado de ser ese 'oscuro objeto del deseo' por parte de las potencias extranjeras apoyando a diferentes actores. En este caso, ese apoyo ha sido en pos del retorno a la supuesta 'estabilidad' que representan los regímenes autoritarios para sus propios intereses, prolongando con sus acciones la duración de los conflictos.

En ese contexto, y a pesar de que las condiciones que una vez hicieron posible la irrupción de la Primavera Árabe continúan vigentes -como el malestar económico, la frustración social y la ausencia de libertades- las mencionadas fuerzas profundas han estado operando de forma interrelacionada, manifestándose en los tres conflictos irresueltos. El resultado, sin más, ha sido la generación de clivajes, nuevas dinámicas y sinergias en un contexto regional intrínsecamente complejo, caracterizado por equilibrios que no han dejado de ser frágiles e inciertos en el MENA.

\section{Referencias bibliográficas}

Amirahmadi, H. (2015). Dark geopolitics of the Middle East. How the Region's Autocrats and Foreign Intruders Created Growing disorder. The Cairo Review, 18, pp. 86-94.

Bordón Osorio, J.(2020). Las prioridades «ciber» entre los Estados MENA. Real Instituto el Cano. Recuperado de: https://blog.realinstitutoelcano.org/las-prioridades-ciber-entrelos-estados-mena/ 
Chalkraft, J.(2014). Egypt's 25 January Uprising, Hegemonic Contestation, and the Explosion of the Poor En F. A. Gerges (Ed.), The New Middle East. Protest and Revolution in the Arab World (pp. 155-179). Cambridge, Reino Unido: Cambridge University Press.

Denoeux, G.(2002). The forgotten SWAMP: Navigating political Islam. Middle East Policy, 9, pp. 56-81.

Droz-Vincet, P.(2014). The military amidst the uprising ant the transformations of Arab world. En F. A. Gerges (Ed.), The New Middle East. Protest and Revolution in the Arab World (pp. 180-208). Cambridge, Reino Unido: Cambridge University Press.

Droz-Vincet, P. (2018). The Arab States after the Uprisings: 'Transitions,' Rebuilt Authoritarianisms and Collapsing States. En S. Florensa, EMed. MediterraneanYearbook 2018 (pp. 29-35). Barcelona, España: European Institute of the Mediterranean.

Duroselle, J. B. (1974). Europa de 1815 a nuestros días. Vida política y relaciones internacionales. Barcelona, España: Ed. Labor (tercera edición).

Foyth, J. y Saione, M. (2021). Del despertar social a la crisis humanitaria: avances y retrocesos en el escenario yemení. En Paredes Rodríguez, R.(comp.), A diez años de la Primavera Árabe. Los desafios de una región convulsa (pp. 109-140). Rosario, Argetina: UNREditora.

Goldstone, J. (2011). Las revoluciones de 2011 y su interpretación. Foreign Affairs Latinoamérica, 11 (3), pp. 60-70.

Hernando de Larramendi, M. (2011). Del malestar social a la protesta política árabe. Política Exterior XXV (140), pp. 44-54.

Karbalan, M.(1 de marzo de 2020). El futuro de Siria está en manos de terceros. Política Exterior, Madrid, marzo - abril (194). Recuperado de: https://www.politicaexterior. com/articulo/futuro-siria-esta-manos-terceros/

Katulis, B. (2015). Alianzas y equilibrios de poder en Oriente Medio. Afkar / Ideas, 44. Recuperado de: https://www.iemed.org/publication/alianzas-y-equilibrios-de-poder-enoriente-medio/

Kaush, K. (8 de enero de 2018). Cibergeopolítica y estabilidad en Oriente Medio. Política Exterior, enero/febrero (181). Recuperado de: https://www.politicaexterior.com/ar ticulo/cibergeopolitica-y-estabilidad-en-oriente-proximo/

Khader, B. (2011). Túnez o la golondrina de la primavera árabe. Política Exterior, XXV (140), pp. 56-65.

Khamis, S. (2020). A battle of two pandemics coronavirus and digital authoritarianism in the Arab world. En M., Sexton (), Cyber War \& Cyber Peace in the Middle East: Digital Conflict in the Cradle of Civilization. Washington D. C., Estados Unidos: Middle East Institute.

Korany, B. (2011). De la excepcionalidad árabe a la 'Primavera árabe'. Afkar / Ideas, 30. Recuperado de: https://www.iemed.org/publication/de-la-excepcionalidad-arabe-a-laprimavera -arabe/

Lynch, M. (2016). The New Arab Wars. Uprising and anarchy in the Middle East. Nuevva York, Estados Unidos: BBS.

Martín Muñoz, G. (2013). Las transiciones árabes a la democracia: año II. Política Exterior, 27 (151), pp. 72-84.

Masoud, T. (2014). The road to (and from) liberation square. En L. Diamond y M. F. Plattner (Ed.), Democratization and authoritarianism in the Arab world ()., Baltimore, Estados Unidos: Johns Hopkins University Press. 
Medin, R. y Lombardi, B. (2021). Diez años de inestabilidad en Libia: entre la debilidad institucional y el conflicto armado abierto. En R. Paredes Rodríguez (comp.), A diez años de la Primavera Árabe. Los desafíos de una región convulsa (pp. 58-85). Rosario, Argentina: UNR-Editora.

Merle, M. (1978). Sociología de las Relaciones Internacionales. Madrid, España:, Alianza.

Morgus, R. (2018). The Spread of Russia's Digital Authoritarianism. En N. D. Wright, AI, China, Russia, and the Global Order: Technological, Political, Global, and Creative Perspectives (pp. 89-97). Washington D. C., Estados Unidos: United States Department of Defense.

Mumford, A. (2013). Proxy Warfare and the future of conflict. The RUSI Journal, 158 (2), pp. 40-46. Recuperado de https://doi.org/10.1080/03071847.2013.787733

Naciones Unidas (2021). Letter dated 8 March 2021 from the Panel of Experts on Libya Established pursuant to Resolution 1973 (2011) addressed to the President of the Security Council. Digital Library. Recuperado de: https://digitallibrary.un.org/record/3905159? $\ln =\mathrm{es}$

Loos, B. (2021). Los árabes vuelven a tomar el camino de Damasco. Orient XXI. Recuperado de: https://orientxxi.info/magazine/los-arabes-vuelven-a-tomar-el-camino-de-damasco, $\underline{5155}$

OXFAM (2020). Crisis en Yemen. Recuperado de: https://www.oxfam.org/es/ que-hacemos/emergencias/crisis-en-yemen

Paredes Rodríguez, R. (2018). Un análisis constructivista del pensamiento de la Hermandad Musulmana de Egipto y su propuesta identitaria de democracia para el mundo árabe: una amenaza al status quo regional. CUPEA Cuadernos de Política Exterior Argentina (Nueva Época), 127, pp. 43-62.

Paredes Rodríguez, R. (2021). Israel, ciberpotencia regional. Dossier Le Monde Diplomatique, 264.

Polyakova, A. y Meserole, C. (2019). Exporting digital authoritarianism: The Russian and Chinese models. Democracy \& Disorder, agosto. Refslund Hamming, T. (2019). A Phoenix Rising from the Ashes? Daesh after its Territorial Losses in Iraq and Syria. PerspectiveonTerrorism, 13 (3).

Renouvin, P. (1990). Historia de las Relaciones Internacionales. Siglo XIX y XX. Madrid, España: Akal Textos (2da edición).

Rosenau, J. (1997). Demasiadas cosas a la vez. La teoría de la complejidad y los asuntos mundiales. Revista Nueva Sociedad, 148.

Sadiki, L. (2009). Like father, like son: dynastic republicanism in the Middle East. Washington D.C., Estados Unidos: Carnegie Endowment for International Peace.

Soliman, M. (2020). The rise of digital authoritarianism in the Middle East. En M. Sexton, Cyber War \& Cyber Peace in the Middle East: Digital Conflict in the Cradle of Civilization (). Middle East Institute.

Yahya, M. (2019). Middle East's lost decades. Foreign Affairs, 98 (6). 